\title{
A Comprehensive Survey on Participation of China's Social Organizations in Community Governance in Recent Years
}

\author{
Zhouqin $\operatorname{Tan}^{1} \&$ Shuyang $\mathrm{Ou}^{1}$ \\ ${ }^{1}$ School of Political Science and Public Management, Southwest University, Chongqing, China \\ Correspondence: Shuyang Ou, School of Political Science and Public Management, Southwest University, \\ 400715 Tiansheng Rd\#2, Beibei Region, Chongqing, China. Tel: 86-136-3776-9886. E-mail: \\ 13637769886@163.com
}

Received: October 31, 2013 Accepted: December 10, 2013 Online Published: January 27, 2014

doi:10.5539/ass.v10n3p159 URL: http://dx.doi.org/10.5539/ass.v10n3p159

\begin{abstract}
Social organizations is one of the important forces in our community governance, it has played a very important role in solving the difficulties in social management, promoting and enhancing the level of community governance. This paper collates and summarizes the related literatures on participation of China's social organizations in community governance in recent years from the following two dimensions: government and social organizations. On this basis, the author analyzes the features of current researches, and then put forward the directions of future research.
\end{abstract}

Keywords: social organizations, community governance, comprehensive survey

\section{Introduction}

Since the conducting of reform and opening-up policy, social organizations have grown quickly in our country, and are playing a more and more important role in the economy, society, culture and other fields. It has become a common academic concern that how can social organizations participate in community governance effectively and undertake the social management functions transferred from governments and enterprises better. Through a comprehensive study on the recent researches, we can generalize them from the following two basic perspectives: one is the government; the other is the social organizations. We can roughly draw the outline of theoretical researches on participation of China's social organizations in community governance in recent years from a comprehensive survey on relevant research achievements from the above two perspectives.

\section{Researches on Participation of China's Social Organizations in Community Governance from the Perspective of Government}

In recent years, studies about participation of China's social organizations in community governance from the government perspective have been mainly focused on the establishment and improvement of a relevant legal system, the improvement of relationship between government and social organizations, the classification management of social organizations, the innovation of social organizations registration and management system, the construction of network of social democratic and equality, the strengthening of the training efforts to social organizations, the transformation of government functions, and the increase of government's efforts to purchase public service.

\subsection{Researches about the Improvement of Relevant Legal System}

A sound law system is one of the indemnifications and basic conditions for social organizations to participate in community governance. Li Xiaochen (2011) believes that we should develop a basic legislation to define the fundamental problems met by non-governmental organizations when participating in community governance, and to provide a legal basis for them to participate in community governance. From the perspective of pluralistic governance, Zhou Yaohong (2010) proposes that the relevant rules and regulations should be strengthened to guarantee the rights of social organizations while participating in the management of public service affairs.

\subsection{Researches on the Improvement of the Relationship between Government and Social Organizations}

Xiao Fei (2011) proposes that government must change its concepts of governance, treat social organizations as partners, and work together with it to promote the innovation and reform of community governance. In order to 
innovate the path for social organizations to participate in community governance, Gao Hong (2011) puts forward that government should recognize not only the existence of social organization, but also its essential functions in community governance. Besides, the government should change the traditional government-controlled management model, and strengthen its efforts to cultivate social organizations.

\subsection{Researches about the Classification Management of Social Organizations}

Jie Qingyan (2012) proposes a three-tier classification method: firstly, we can divide social organizations into public welfare social organizations and mutually beneficial social organizations by whether you need to pay for the service or not; secondly, according to the area they belong to, the public welfare social organizations can be divided into voluntary obligations organizations, class charity organizations and social welfare organizations, the mutually beneficial social organizations can be classified as community service organizations, science and education organizations, product and economic organizations. What's more, we can classify social organizations into different sorts on the basis of their social functions. Xiao Fei (2011) puts forward that government should manage social organizations according to the category it belongs to under the guidance of these principles, such as scientific management and convenient service.

\subsection{Researches on the Innovation of Social Organizations Registration and Management System}

The registration system is not only the basic institution for social organizations to participate in community governance, but also the key factor that influences the participating effectiveness. Gao Hong (2011) advances that government departments should gradually reduce the restrictions of qualification for registration, broaden the conditions for registration, simplify the registration process, and establish a comprehensive set of social organization registration system. Wang Ming and Ding Jingjing (2013) believe that a unified registration system should be built to make social organizations obtain legal status through effective registration, and provide a legal basis for the implement of its activities.

\subsection{Researches on the Construction of Network of Social Democratic and Equality}

With the arrival of information age, information has gradually become an vital resource and indemnification for social organizations to participate in community governance effectively. To promote the openness and transparency of information, Li Xiaochen (2011) brings forward that we should facilitate the construction of a network of social democratic and equality to give full play to the role of social organizations in coordinating the relationship between administrations and managers, and improve the rationality and transparency of policy-making in social management. From the perspective of promoting information publicity, Zhou Yaohong (2010) holds that the government should not only improve the level of democratization and science in planning and public decision-making, but also expand the extent of openness and transparency of government information. Besides, collecting and listening to the feedback from different social groups regularly is necessary.

\subsection{Researches on the Strengthening of Training Efforts to Social Organizations}

Social organizations is a part of the community essentially, so Xu Zurong (2011) proposes that government should cultivate and support the development of social organizations, provide institutional legal indemnification for its growth, and eliminate external barriers in the up growth and development of social organizations. From the perspective of policy and financial support to social organizations, Deng Hui (2013) argues that government should give policy and financial support to the activities of social organizations to participate in community governance, but also establish and maintain a good collaborative relationship between government and social organizations.

\subsection{Researches on the Transformation of Government Functions}

To deepen the transfer process of government functions and redefine its orientation, government departments should complete the transition from "control-oriented government" to "service-oriented government" as quickly as possible, and transform those functions can be undertook by social organizations to them. Zhou Yaohong (2010) believes that government should exhaustively solve these problems, such as the offside, dislocation, and vacancy of its functions in administration, and try to be a good collaborator, facilitator to social organizations.

\subsection{Researches on the Increase of Government's Efforts to Purchase the Public Services}

Participation in the supply of public goods and public services is one of the most important ways for social organizations to participate in community governance. Most domestic scholars agree that it is necessary for government to increase efforts to purchase public services. Research by Wang Ming and Ding Jingjing (2013) supports that the government departments should gradually withdraw from some areas of social management, and establish a sound participation mechanism and approach for social organizations to undertake social services. 
Besides, a co partnership between government and social organizations is required. In the specific ways to establish this relation, Gao Hong (2011) suggests that the government could take advantage of the project management, and provide financial support to social organizations by purchasing public services.

\section{Researches on Participation of China's Social Organizations in Community Governance from the Perspective of Social Organizations}

In recent years, domestic scholars' studies on participation of China's social organizations in community governance are expanded not only from the angle of government, but also from the social organizations. These researches are mainly focused on the sources of social organization's capitals, the management of qualified personnel, the cooperation between social organizations and the construction of a supervision and management system of social organizations, the diversity in the form of social organizations, and the path selection for industry associations to participate in community governance.

\subsection{Researches on the Sources of Social Organization's Capitals}

Capitals has always been an important factor which restricts the development of social organizations and the effectiveness for it to participate in community governance. Li Xiaochen (2011) believes that social organizations can raise the funds needed to keep itself working and participate in community governance from the following three approaches: firstly, the most fundamental one, seek government subsidies actively; secondly, increase the proportion of private donations by the strengthening of public relations work, the improvement of its visibility and credibility, and the establishment of specialized fundraising agency; last but not the least, transfer the technological achievements and provide information technology consulting service. Xiao Fei (2011) also proposes that social organizations should enhance the public's understanding of social organizations' public targets, and services by increasing efforts to publicize positively. He considers that it's also indispensable for social organizations to maintain long-term cooperative relations with the investors and enhance their own "hematopoietic feature".

\subsection{Researches on the Management of Qualified Personnel}

A group of talent which is scientifically and rationally deployed is the guarantee for social organizations to participate in community governance effectively. Li Xiaochen (2011) brings forward that we should pay more attention to the vocational training of practitioners to improve their professional quality and capacity. He advances that an incentive system, competitive system, and a scientific management mechanism, which is conducive to the development and management of talents, should be established. Xiao Fei (2011) proposes that, to improve the management and construction level of social organizations, they will have to attach great importance to the training of employees and the cultivation of professionals.

\subsection{Researches on the Cooperation between Social Organizations}

Different type of social organizations has its unique advantages in their respective fields. Gao Hong (2011) proposes that we should strengthen the linkages between social organizations and promote the integration of resources and efforts between them. The administrative resources, marketing resources and social resources scattered in various social organizations can be integrated through effective coordination and cooperation mechanisms. And through this way, we can form a joint force for social organizations to participate in community governance.

\subsection{Researches on the Construction of the Supervision and Management System of Social Organizations}

Without an effective supervision and management mechanism, social organizations cannot participate in community governance scientifically or efficiently. From the perspective of regulatory subject, Xiao Fei (2011) argues that government departments should be the body to strengthen the oversight of social organizations, monitor the daily activities of social organizations according to the law, and supervise social organizations to undertake and carry out the functions transferred from governments lawfully, normatively and orderly. However, Wang Ming and Ding Jingjing (2013) advocate that we should change the status that the government sector is as the single supervisory body to build a accountability and evaluation system with a wide community participation. And this system should be under the leadership of party and government organs represented by civil affairs department. Besides, the overall level of social organizations to participate in community governance can be improved by the intervention of accountability and oversight mechanism, and the continuous construction of its organizational capacity. Gao Hong (2011) also approves to build a regulatory mechanism, which contains a self-regulatory system within social organizations, a scientific supervision system and a justifiable social supervision mechanism, to achieve effective supervision of social organizations to participate in community governance. 


\subsection{Researches about Diversity in the form of Social Organizations}

Nowadays, the field and scope of China's social organizations participating in community governance effectively is still very narrow. Wang Ming and Ding Jingjing (2013) brings forward that we should try to develop various forms of social organizations, to form pluralistic governance under the leadership of party committee with social coordination. They also applaud to widen the field and scope of social organization participating in community governance through the diversification of social organizations.

\subsection{Researches on the Path Selection for Industry Associations to Participate in Community Governance}

Although the method for different types of social organizations to participate in community governance is various, the functions of industry associations participating in community governance are basically affirmed by domestic scholars. In the specific participatory path of industry associations, Xu Zurong(2011) proposes that industry associations should undertake the functions of industry analysis, technical qualification, and preliminary qualification initiatively. To give assistance to the government management, Xu Zurong holds that industry associations should implement government policies, state laws and regulations in the management of enterprise opportunely. Li Xiaochen (2011) considers that since industry associations have some binding effects on its members, they can effectively promote the realization of social fairness and fair market by guiding the construction of fair market credit system validly.

\section{Features and Implications of Domestic Studies on Participation of China's Social Organizations in Community Governance}

Nowadays, academic researches about social organizations to participate in community governance are becoming a research hotspot. After several years of in-depth research, there are quite fruitful research results. By combing the recent research achievements, we can generalize the following research features and enlightenments.

\subsection{Features of the Researches}

\subsubsection{Overfull Specific Researches and Lack of Comprehensive and Macroscopic Studies}

The operating researches mainly focus on the practical plights when social organizations take part in community governance, non-governmental organizations' participation in Mass Emergency management, or how to learn from the experience of foreign social organizations to participate in community governance. So, there are few comprehensive and macroscopic studies about how can social organizations participate in community governance effectively.

\subsubsection{The Theoretical Basis These Researches Relied on Is Rather Out-of-date}

In recent years, with the rapid development of Chinese society and economy, the governance theory is increasingly becoming the theory in accordance with the actual situation of participation of China's social organizations in community governance. While, many scholars still base their studies on social management, and interpret the practical problems from the perspective of social management. The theoretical foundation is relatively backward.

\subsubsection{The Hotspot is Still Inconclusive}

The core issue for the participation of China's social organizations in community governance is how to define the relationship between government and social organizations. Being confined by the indefinite national policies, this issue is still in debate. With the rapid growth of social organizations, different scholars have different opinions on how to develop the relationship between government departments and social organizations, and which of them should be the supervisor. Some of them advocate to establish a "strong government + strong society" relational model, some scholars propose to establish a pattern of relationship that society is the leader gradually, some scholars believe that there should be multiple administration principal to realize pluralistic governance. However, some scholars hold the opposite view that we should calm down and analyze this topic in line with the actual situation in China.

4.1.4 Researches on the Specific Paths for Social Organizations to Participate in Community Governance Is Absent

In recent years, most domestic scholars prefer to analyze the path of social organizations to participate in community governance from wide perspectives, such as legal, institution, government, mode, etc. Researches and interpretations about the specific paths for social organizations to participate in community governance are defective. 


\subsection{Implications of Researches}

Integrating the deficiencies of the studies on participation of China's social organizations in community governance in recent years, as well as analyzing the basic trend of domestic and international researches, we can get the following revelations to our research in the near future:

Firstly, update the theoretical foundation, and expand researches on social organizations to participate in community governance in view of the relatively new theory;

Secondly, pay more attention to the comprehensive study, deepen the level of theoretical research, and carry out macro researches on the orientation of the construction of the relation between government and social organizations. In this way, we can offer a guidance and theoretical reference to other researches on participation of social organizations in community governance.

Thirdly, related studies should base on the reality and localization. We should spend more energy to study the specific ways for certain type of social organizations to participate in community governance and the coordination of the relationship between the government and social organizations during the participatory process. Besides, more researches about the development of social organizations and the obstacles when they participate in community governance should be implemented by academics.

\section{Conclusion}

With the large-scale transition of our economic system and the accelerated process transformation of government functions, part of the social management and service functions shouldered by the units gradually transfer to the society. Social organizations, as the group form of people's common activities, have become an important force in community governance. The new central government is trying to adjust the relationship between government and society, further transform the functions of government, and make social organizations' functions be used to its fullest potential. Systematic carding of the related literatures on the participation of social organizations to in community governance from government and social organizations can be an important reference to innovate the researches on participation of China's social organizations in community governance, and enhance the level of participation of China's social organizations in community governance.

\section{References}

Deng, H. (2013). The Practice and Enlightenment of Japanese and Singaporean Society Organizations in the Community Governance. Journal of the Party School of CPC Xiamen Municipal Committee, 2, 38-41.

Gao, H. (2011). The Pattern Innovation and Institutional Guarantee for Community-based Social Organizations to Participate in Social Construction. Social Science, 6, 76-83.

Jie, Q. Y. (2012). On the Classification and Management of Social Organizations. Intelligence, 25, 333.

Li, X. C. (2011). Path Selection of Chinese Non-governmental Organizations to Participate in Community Governance. Chuang Cheng, 2, 68-69.

Lv, Y. J. (2012). The Essence of Social Management Innovation Lies in the Reconstruction of the Relationship Between Government and Society. Journal of Liaoning Administration College, 6, 23-25.

Ngok, K. L., \& Deng, Z. P. (2013). On the Five Approaches to Understanding Social Management and Its Innovation. Wuhan University Journal (Philosophy \& Social Sciences), 3, 28-34.

Wang, M., \& Ding, J. J. (2013). The Basic Experience of Social Organizations Participating in Social Management Innovation. Chinese Public Administration, 4, 65-67.

Xiao, F. (2011). Dilemma and Routing Path Selection for Social Organizations to Participate in Community Governance. Journal of the Part School OFC.P.C. Qingdao Municipal Committee, 2, 65-68.

Xu, Z. R. (2011). Value Orientation and Path Selection: Experiences Logic of Social Organizations to Participate in Social Management Innovation from Collaborative Governance Perspective. Chinese Public Administration Society Annual Conference (2011) - "Strengthen the administrative research, and promote government reform" Symposium.

Zhou, Y. H. (2010). Expand Masses' Participation: Explore NGO Participating Social Governance, Chinese Sociological Association Annual Conference (2010) - "Study on Social Stability and Social Management Mechanism" Forum Proceedings, 1-10. 


\section{Copyrights}

Copyright for this article is retained by the author(s), with first publication rights granted to the journal.

This is an open-access article distributed under the terms and conditions of the Creative Commons Attribution license (http://creativecommons.org/licenses/by/3.0/). 